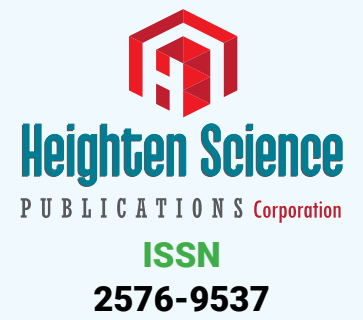

*Address for Correspondence: Mohamed Abdelhamid, Surgery Department, Faculty of Medicine, Beni Suef, Egypt, Tel: 00201062531899; Email: m.salah10.59@gmail.com;

mohamedsalah_2000@hotmail.com

Submitted: 01 January 2019

Approved: 06 February 2019

Published: 07 February 2019

Copyright: (C) 2019 Abdelhamid MS, et al. This is an open access article distributed under the Creative Commons Attribution License, which permits unrestricted use, distribution, and reproduction in any medium, provided the original work is properly cited

Keywords: Cholecystectomy open laparoscopic complications

Check for updates
Research Article

\section{Risk definition in Laparoscopic versus Open Cholecystectomy}

\author{
MS Abdelhamid ${ }^{1 *}$, TM Nabil' ${ }^{1}$, HA Nafady¹, AZ Garib² and SS \\ Soliman ${ }^{3}$
}

'Surgery Department, Faculty of Medicine, Beni Suef, Egypt

${ }^{2}$ Surgery Department, October $6^{\text {th }}$ Faculty of Medicine, Giza, Egypt

${ }^{3}$ Surgery Department, Faculty of Medicine, Fayoum, Egypt

\section{Abstract}

Nothing without risk. As cholecystectomy is one of the most common procedures, any minor risk will be a mass volume. This study was to define the magnitude of that risk. In the study were 1486 patients between Feb. 2009 and April. 2018. Open in 292 (19.6\%), 1194 (80.4\%) laparoscopically, 1086 [91\%] completed so and $108(9 \%)$ converted. There were $18(1.2 \%)$ with bile duct injury. $1(0.3 \%)$ in the open group and $17(1.4 \%)$ in the laparoscopic group. 9 diagnosed during surgery, 4 with jaundice, 2 early and 2 late, 5 with leak. Statistically the operative injury is insignificance in the 2 groups $(P<0.3)$. The jaundice was significantly high in the laparoscopic group of patients $(P<0.045)$. Also the bile leak $(P<0.028)$. The same for morbidity $(P<0.01$. The revers was for mortality $(P<0.04)$

Conclusion: The incidence of $\mathrm{CBD}$ injury in the literature is less than the actual rate Laparoscopic interventions have a higher rate of injury and the proximal ducts are at higher risk.

\section{Introduction}

Common bile duct injury may cause mortality as high as 5\% [1]. Mostly not recognized during surgery. As gall bladder stones are very prevalent, and the number of interventions is massive, so even if the rate of injury is small the number at the end is big [2].

Now it is known that the laparoscopic approach is more risky with up to 15 fold increase in the risk $[3,4]$. The rate of injury is decreasing [5].

The proximal duct is at greater risk. Intra operative cholangiogram may be the only way to decrease the rate of injury [6]. There are many patterns for injury, the first is mistaking the common duct for the cystic, finally the distal duct clipped, the upper transected. In the second the distal clips are placed on common duct and the proximal on the cystic, ending with cystic t stump leak and distal duct obstruction. The third is tenting of the CBD; the result is the excision of the short segment of common duct with the cystic duct [7]. Right hepatic duct mistaken for the cystic [8].

\section{Patients and Methods}

Between February 2009 and April 2018, 1486 cholecystectomies were done for gall stones, none of them were acute. The main indications for open cholecystectomy were any contraindication for insufflation. 1285 were females, 201 were males with mean age of 52 with SD +-9.6 years.

Approval of the ethical committee is taken with a written consent from the patients. 


\section{The operative procedures}

A - Laparoscopic cholecystectomy started by pneumoperitoneum with the use of veruss needle, introducing $\mathrm{Co} 2$ to peritoneal cavity with intraabdominal pressure at $12-14 \mathrm{mmHg}$. Four trocars were used.

B - Open cholecystectomy through right paramedian incision or right subcostal incision.

C - We applied Strasburg scale classification for our injuries.

\section{Statistical analysis}

The data obtained were statistically analyzed using fisher's test to obtain the Z value and from the standardized table. The degree of probability is obtained [9].

\section{Results}

1486 cholecystectomies were operated upon. 292 (19.6\%) were open, 1194 (80.4\%) were laparoscopic of which 1086 (91\%) completed laparoscopically, 108 (9\%) converted (Table 1). Out of the 292 open, only $1(0.3 \%)$ had common bile duct injury, during surgery (Table 2). Out of the 1086 laparoscopically completed, there were $4(0.4 \%)$ complicated with with jaundice, two of them within 3 months. In the same group there were also 4 cases $(0.4 \%)$ with leak (Table 3 ). In the converted, there were $8(7.4 \%)$ injury during surgery, and 1 case $(0.9 \%)$ with bile leak (Table 4$)$.

There were 8 cases $(0.7 \%)$ of recognized intra-operative injury (R.I.O.I) among the 1194 cases. The 4 cases of jaundice had an incidence of $0.35 \%$ in the Laparoscopic group (1194) that was $0.4 \%$ among those ended laparoscopically(1086) (Tables 3,5). The post operative bile leak was $5(0.4 \%)$, four in the laparoscopic group (Table 3 ) and one in the converted group (Table 4).

There was one case of recognized intraoperative injury R.I.O.I in the open patients $(0.3 \%)$, and the difference was non significant $(\mathrm{P}<0.3)$ (Table 6).

In respect to jaundice, $4(0.35 \%)$ among laparoscopic patients, and no in the open $(\mathrm{P}<0.045)$ significant (Table 7).

The bile leak in the laparoscopic patient's was5 (0.4\%) cases, no bile leak in the open patients. The difference $(\mathrm{P}<0.028)$ was statistically significant (Table 8$)$.

The reported mortalities were two cases, one in each group, with a statistically significant difference $(\mathrm{P}<0.04)$ (Tables 9,10).

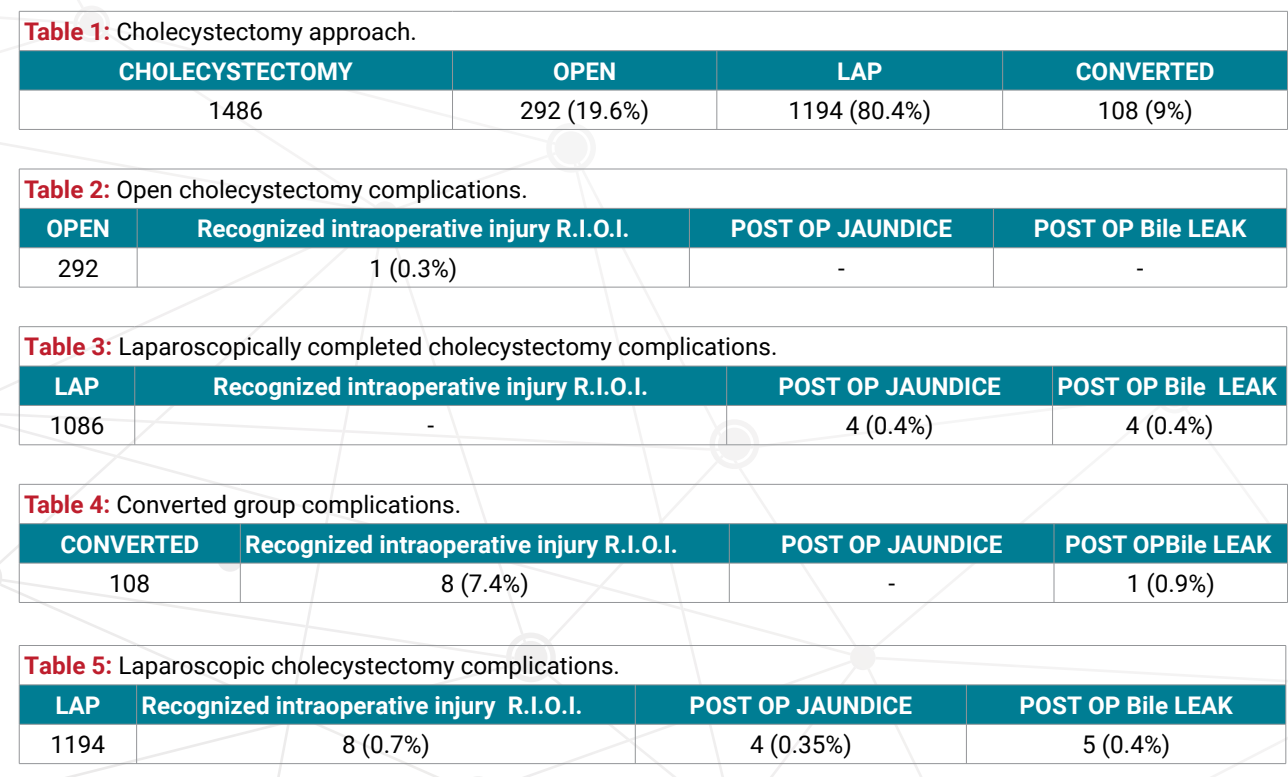




\begin{tabular}{|c|c|c|c|c|}
\hline APPROACH & NO & \multicolumn{2}{|c|}{ Recognized intraoperative injury R.I.0.I } & STATISTICS \\
\hline Open & 292 & \multicolumn{2}{|r|}{$1(0.3 \%)$} & $Z=1.05$ \\
\hline Laparoscopic & 1194 & \multicolumn{2}{|r|}{$8(0.7 \%)$} & $P<0.3 \mathrm{NS}$ \\
\hline \multicolumn{5}{|c|}{ Table 7: Comparison of post-operative jaundice. } \\
\hline \multicolumn{2}{|c|}{ APPROACH } & NO & POST OP JAUNDICE & STATISTICS \\
\hline \multicolumn{2}{|l|}{ Open } & 292 & - & $=2.05$ \\
\hline \multicolumn{2}{|l|}{ Laparoscopic } & 1194 & $4(0.35 \%)$ & $P<0.045 \mathrm{~S}$ \\
\hline \multicolumn{5}{|c|}{ Table 8: Comparison of post- operative leak. } \\
\hline \multicolumn{2}{|c|}{ APPROACH } & 10 & POST OP Bile LEAK & STATISTICS \\
\hline Open & \multicolumn{2}{|c|}{292} & \multirow{2}{*}{$5(0.4 \%)$} & $Z=2.22$ \\
\hline Laparoscopic & \multicolumn{2}{|c|}{1194} & & $P<0.028 \mathrm{~S}$ \\
\hline \multicolumn{5}{|c|}{ Table 9: Morbidity significance. } \\
\hline \multicolumn{2}{|c|}{ APPROACH } & NO & MORBIDITY & STATISTICS \\
\hline \multicolumn{2}{|l|}{ Open } & 292 & $1(0.3 \%)$ & $Z=2.75$ \\
\hline \multicolumn{2}{|l|}{ Laparoscopic } & 1194 & $17(1.4 \%)$ & $\mathrm{P}<0.01 \mathrm{~S}$ \\
\hline \multicolumn{2}{|c|}{ APPROACH } & NO & MORTALITY & STATISTICS \\
\hline \multicolumn{2}{|l|}{ Open } & 292 & $1(0.3 \%)$ & $Z=2.05$ \\
\hline \multicolumn{2}{|l|}{ Laparoscopic } & 1194 & $1(0.08 \%)$ & $P<0.04 S$ \\
\hline
\end{tabular}

\section{Discussion}

Technical difficulties or complications are the main causes of conversion [10]. In order not to miss injury a high awareness of its possibility is needed [11].

The mechanism of injury is different between open and laparoscopic. In the laparoscopic it is more proximal and extensive [12].

The patient may develop jaundice after an uneventful discharge from the hospital [13].

1486 cholecystectomy were in the study, 292 (19.6\%) were open, 1194 (80.4\%) initiated laparoscopically, then108 (9\%) converted, these goes hand in hand with Buanes et al. [10], 20\% open surgery $79.8 \%$ started laparoscopically, and $10.2 \%$ converted. Mostly open to guard against contraindication of insufflation, Pineres et al. [11]. Conversion is usually asking for the safety and to save time after no progression Tokumura et al. [8], and Giuliante et al. [12], who had conversion rate of 5.2\% in patients with simple cases and $37.5 \%$ in patients with difficult cases.

The rate of injury account to $0.7 \%$ of patients subjected to gall bladder removal [13]. This incidence appear to be less than the actual rate. In our study $18(1.2 \%)$ patients suffered injured, $1(0.3 \%)$ in the open surgery, 17 (1.4\%) during laparoscopic surgeries. In our work the general incidence was $1.2 \%$ while it was $0.7 \%$ in the series of Paczynski et al. [17], while its frequency was $0.2 \%$ to $0.4 \%$ with Mercado et al. [18]. In our work injury happened in $0.3 \%$ in the open surgery this goes hand in hand with Murr et al. [9], where their patients suffered from $0.2 \%$ to $0.4 \%$ injuries in the open interventions, in the same time their patients suffered from $0.5 \%$ to $0.8 \%$ injury laparoscopically while it was $1.4 \%$ in our work while it was $0.59 \%$ in the series of Mahatharadol [19], but Calvete el al. [5], got injury as high as $1.4 \%$. In the stream is the work of Buanes et al. [14], who recorded $0.8 \%$ injuries after open while we got $0.3 \%$.That is to say that the reported incidence in the literature [13], is less than the reported incidence in our work and in the work of others $[5,9,14,17,19]$.

The 18 insult happened, $9(50 \%)$ recognized on table $1(3 \%)$ in open intervention and $8(47 \%)$ in laparoscopic surgeries, this is in accordance with Mercado et al. [18]. With no significant difference $(\mathrm{P}<0.3) .4$ cases $(0.35 \%)$ of jaundice in the laparoscopic 
group only with significant difference $(\mathrm{P}<0.045)$. Mentioning the leak, zero\% in open, $0.4 \%$ in laparoscopic and $0.9 \%$ in converted with a statistically significant $(\mathrm{P}<0.028)$ difference, these is in contrast to Buanes et al. [14], who recorded $2.4 \%$ after open while in ours $0.4 \%$ also $4.2 \%$ after converted while in ours $0.9 \%$. The morbidity was higher in laparoscopic intervention and was statistically $(<0.01)$ significant, in contrary to mortality was higher in the open with significant difference $(\mathrm{P}<0.04)$, like that of Buanes et al. [14], who found it to be significant (0.01), in our work mortality took place 4 times more frequently after open operations while it is 10 times more with others $[20,21]$.

Injury with associated leak may end with serious septic complication. Jaundice may be early or late therefore follow up is needed.

\section{Conclusion}

The incidence of CBD injury in the literature is less than the actual rate. Laparoscopic interventions have a higher rate of injury and the proximal ducts are at higher risk.

\section{References}

1. Zha $Y$, Chen $X R$, Luo D, Jin $Y$. The prevention of major bile duct injures in laparoscopic cholecystectomy: the experience with 13,000 patients in a single center. Surgical Laparoscopy, Endoscopy and Percutaneous Techniques. 2010; 20: 378-383. Ref.: https://goo.gl/ovSwkY

2. Archer SB, Brown DW, Smith CD, Branum GD, Hunter JG. Hunter, Bile duct injury during laparoscopic cholecystectomy: results of a national survey. Annals of Surgery. 2011; 234: 549-559. Ref.: https://goo.gl/PP5H5U

3. Flum DR, Koepsell $T$, Heagerty $P$, Sinanan $M$, Dellinger EP. Common bile duct injury during laparoscopic cholecystectomy and the use of intraoperative cholangiography. Arch Surg. 2001; 136 1287-92. Ref.: https://goo.gl/vqzZBZ

4. Gouma DJ, Go PM. Bile duct injury during laparoscopic and conventional cholecystectomy. J Am Coll Surg. 1994; 178: 229-233. Ref.: https://goo.gl/zqhusY

5. Calvete J, Sabater L, Camps B. Bile duct injury during laparoscopic cholecystectomy: Myth or reality of the learning curve? Surg Endosc. 2000; 14: 608-611.

6. Jarnagin WR, Blumgart LH. Operative repair of bile duct injuries involving the hepatic duct influence. Arch Surg. 1999; 134: 769-775. Ref.: https://goo.gl/N8jU3o

7. Branum G, Schmitt C, Baillie J, Suhocki P, Baker M, et al. Management of major biliary complications after laparoscopic cholecystectomy. Ann Surg. 1993; 217: 532-541. Ref.: https://goo.gl/xTeK86

8. West Cott CJ, Pappas TN. Benign biliary strictures. In Cameron JL (ed). Current surgical therapy.: St. Louis, Missouri, Mosby. 1998; 425-434.

9. Swinscow TDV, Campell MJ. Statistics at Square one. In TDV Swinscow (ed). Plymouth, Latimer trend \& Company Ltd. 1996; 1-138. Ref.: https://goo.gl/9nGN2n

10. Tokumura H, Rikiyama T, Harada N, Kakyo M, Yamamoto K. Laparoscopic biliary surgery. Nippon Geka Gakkai Zasshi. 2002; 103: 737-734. Ref.: https://goo.gl/ZJsg4y

11. Sandha GS, Bourke MJ, Haber GB, Kortan PP. Endoscopic therapy for bile leak based on a new classification: results in 207 patients. Gastrointestinal Endoscopy. 2004; 60: 567-574. Ref.: https://goo.gl/Hx7XKU

12. Murr MM, Gigot JF, Nagorney DM, Harmsen WS, Ilstrup DM, et al. Long term results of biliary reconstruction after laparoscopic bile duct injuries. Arch Surg. 1999; 134: 604- 610. Ref.: https://goo.gl/dg1b16

13. Machado NO. Biliary Complications Post Laparoscopic Cholecystectomy: Mechanism. Preventive Measures, and Approach to Management: A Review. Diagnostic and Therapeutic Endoscopy. 2017: 967017. Ref.: https://goo.gl/ryhiQG

14. Buanes $T$, Wauge $A$, Mjaland $O$, Solheink K. Bile leak after cholecystectomy significance and treatment. Int surg. 1996; 81: 276-279. Ref.: https://goo.gl/gJfVbR

15. Pineres $\mathrm{G}$, Yama Kawa $\mathrm{T}$, Kasugai $\mathrm{H}$, Fukuda $\mathrm{N}$, Ishiyama J, et al. Common bile duct stones. J hepato biliary Pancreat Surg. 1998; 5: 97-103. Ref.: https://goo.gl/AZ9yVc 
16. Giuliante F, Vellone M, Fianchini M and Nuzzo G. The surgical risk of laparoscopic cholecystectomy. Ann Ital Chris. 2016; 69: 723-729. Ref.: https://goo.gl/vQEBEq

17. Paczynski A, Koziarski T, Stanowski E, Krupa J. Extrahepatic bile duct injury during laparoscopic cholecystectomy. Med Sci Monit. 2002; 8: 438-440. Ref.: https://goo.gl/oemJB5

18. Mercado MA, Chan C, Orozco H, Cano-Gutiérrez G, Chaparro JM, et al. To stent or not to stent bilioenteric anastomosis after iatrogenic injury. Arch surg. 2002; 137: 60-63. Ref.: https://goo.gl/uQJ3QL

19. Mahatharadol V. Bile duct injuries during laparoscopic cholecystectomy: Anaudit of 1522 cases. Hepatogastroenterology. 2014; 51: 12-40. Ref.: https://goo.gl/cMfz6L

20. Heise M, Schmidt SC, Adler A, Hintze RE, Langrehr JM, et al. Management of bile duct injury following laparoscopic cholecystectomy. Zentralbl Chir. 2003; 128: 944-951. Ref.: https://goo.gl/YM5EEt

21. Ludwig K, Bernhardt J, Steffen H, Lorenz D. Contribution of I.O.C. to the incidence and outcome of common bile duct injury during LC. Surg Endosc. 2015; 16: 1098-1104. Ref.: https://goo.gl/SFkXnS 